\title{
Solvent Effects on the Kinetics of the Dakin-West Reaction
}

\author{
Ayman Abdelaziz Osman ${ }^{1,2}$ \\ ${ }^{1}$ Department of Chemistry, College of Science and Home Economic, Bisha University, Bisha, Saudi Arabia \\ ${ }^{2}$ Departmen of Chemistry, College of Science and Education, University of West Kurdofan, EL Nuhud, Sudan
}

\section{Email address:}

aymanziz@yahoo.com

\section{To cite this article:}

Ayman Abdelaziz Osman. Solvent Effects on the Kinetics of the Dakin-West Reaction. American Journal of Physical Chemistry. Vol. 5, No. 6, 2016, pp. 118-127. doi: 10.11648/j.ajpc.20160506.13

Received: November 21, 2016; Accepted: December 5, 2016; Published: January 12, 2017

\begin{abstract}
The rate of the Dakin-West reaction have been investigated in $\mathrm{Me}_{2} \mathrm{SO}$, THF and $\mathrm{CH}_{3} \mathrm{CN}$ at the temperature range (55-70) are reported. First order rate constants were obtained in each case. A Bronsted slope was found to be equal -0.0277 indicates that the transition state is very reactant-like and the proton has barely moved. Further, the solvent effect was considered from two points of mechanistic view: the thermodynamic transfer function of $\mathrm{Me}_{2} \mathrm{SO}$ to $\mathrm{CH}_{3} \mathrm{CN}$ and THF where the rate was found to be fast in $\mathrm{Me}_{2} \mathrm{SO}$ and slow in THF and $\mathrm{CH}_{3} \mathrm{CN}$ and the Kirkwood-Buff preferential solvation with aqueous $\mathrm{Me}_{2} \mathrm{SO}, \mathrm{CH}_{3} \mathrm{CN}$ and THF. The techniques supported the proposed transition state structure.
\end{abstract}

Keywords: Dakin-West Reaction, Kirkwood-Buff Theory, Azlactone, Thermodynamic Transfer Function, Solvent Effect, Bronsted Plot, Activity Coefficient

\section{Introduction}

\subsection{The Dakin - West Reaction}

The direct conversion of an $\alpha$ - amino acid (1) into the corresponding acetamido alkyl methyl ketone (2) by the action of acetic anhydride in the presence of pyridine, with the evolution of carbon dioxide was recognized by Dakin and West [1]

$$
\mathrm{R}-\left.\right|_{\mathrm{NH}_{2}} ^{\mathrm{CH}}-\mathrm{COOH}+\left(\mathrm{CH}_{3} \mathrm{CO}\right)_{2} \mathrm{O} \stackrel{\mathrm{py}}{\longrightarrow} \mathrm{R}-\underset{\mathrm{NHCOCH}_{3}}{\mathrm{CH}}-\mathrm{COCH}_{3}+\mathrm{CO}_{2}
$$$$
1
$$$$
2
$$

Dakin and West showed that pyridine could be replaced by alkyl pyridine or sodium acetate. On the other hand acetic anhydride may be replaced by other anhydrides affording for example ethyl-or propyl-ketones in good yields, under modified reaction condition, but, in general, yield diminishes with increasing chain length in the acid anhydride [2, 3].

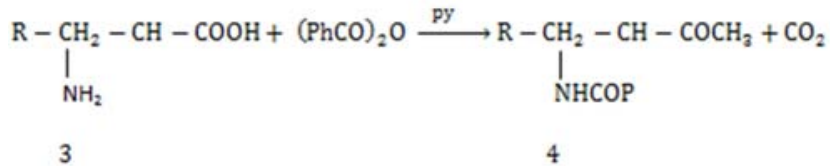

Cleland and Nieman reported that benzoic anhydride gives a moderate yield of phenyl ketone [2]. But neither phthalic anhydride nor acetic anhydride products any ketone from phenyl alanine.

\subsection{Mechanism of the Dakin - West Reaction}

The reaction of glycine (5) with acetic anhydride in the presence of pyridine to give $\alpha$-acetamido alkyl methyl ketone (14). The reaction proceeds through acylation of glycine, cyclization of acylated product to an azlactone (7) and the reaction of azlactone with pyridine to give resonancestabilized carbanion, which reacts with acetic anhydride to give azlactone (9) of the acetamido- $\beta$-keto acid, subsequent conversion of the azlactone to the acetamido ketone (14) and carbon dioxide follows as shown in Figure 1. 


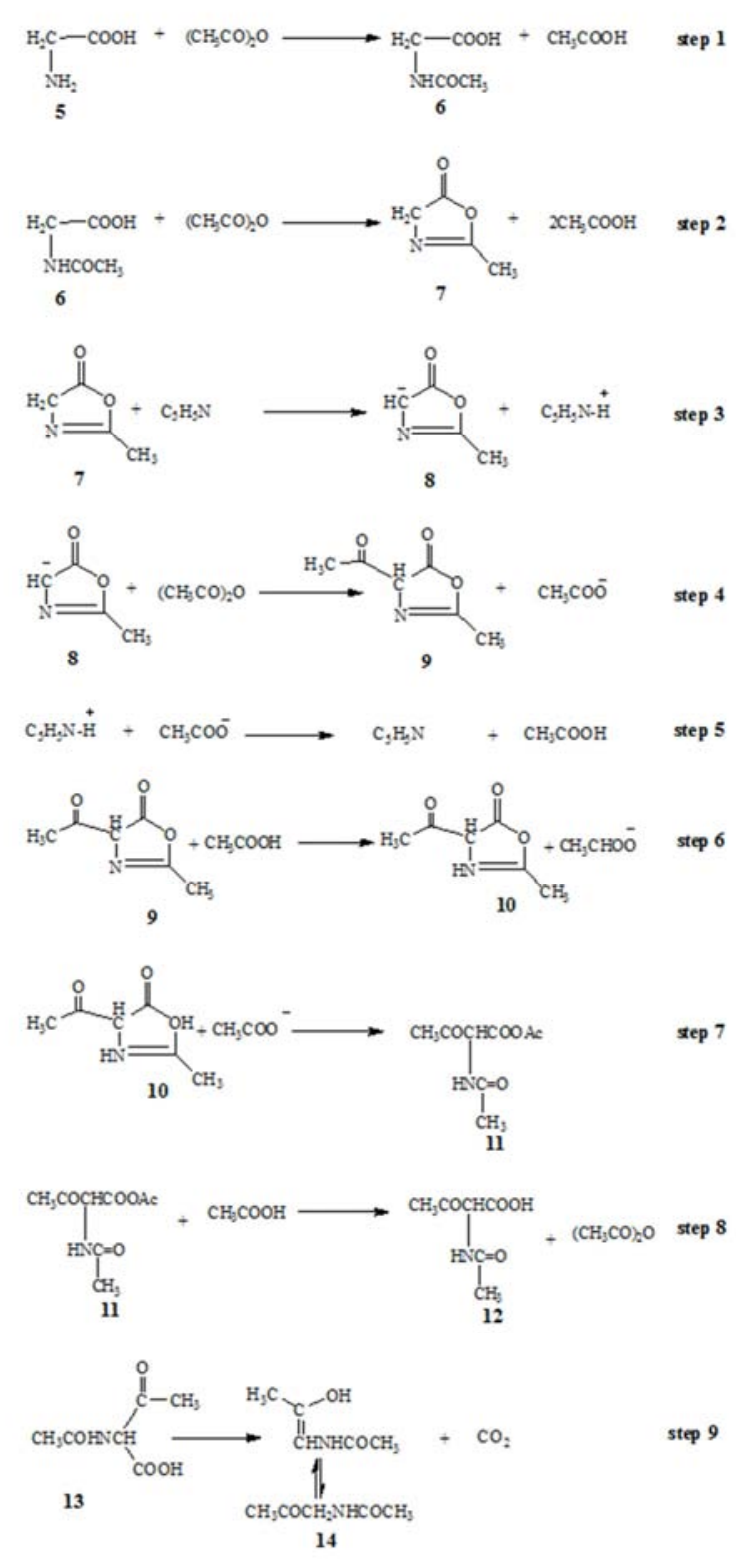

Figure 1. Mechanism of the Dakin-West Reaction.

\subsection{Base Catalysis of the Dakin-West Reaction}

The behavior of an acid or base on the ionization (exchange a proton with solvent) is closely related to its behavior as general acid or base catalyst (exchanging a proton with a substrate). The relationship was quantified by Bronsted and Pederson following their development of the principle of general acid and base catalysis. Their equations are expressed as:

$$
\begin{aligned}
& \log \mathrm{K}_{\mathrm{a}}=\alpha \log \mathrm{K}_{\mathrm{a}}+\mathrm{C}_{\mathrm{a}} \\
& \log \mathrm{K}_{\mathrm{b}}=\beta \log \mathrm{K}_{\mathrm{b}}+\mathrm{C}_{\mathrm{b}}
\end{aligned}
$$

where $K_{a}$ and $K_{b}$ are the rate constant for the acid and base catalyzed reaction respectively and $\alpha, \beta$ and $C$ are constant dependent on the reaction and its condition but independent of the catalyst. Bronsted coefficients equal zero $(\beta=0)$ have been taken as indicative of the transition state is very reactant
- like whereas those $(\beta=1)$ are indicative of the transition state is not reached till the proton is almost fully transferred to the catalyst (3). When the proton is just halfway from reactant to catalyst $(\beta=0.5)([4,5]$

\subsection{Solvent Effect on Reaction Rate}

The solvent effect on reaction rate are best treated in terms of the thermodynamics of hypothetical equilibrium between reactant and transition state, i.e., in the frame of the absolute rate theory rather than collision theory $[7,8]$.

The specific rate of a chemical reaction depends on the standard free-energy difference between reactants and transition state. So the first step in solving the problem of the influence of a solvent on reaction rate is there for the determination of the standard chemical potential of the reactants and transition state in a various solvent.

Any consideration of solvent effect on rates or equilibria must start from solvent activity coefficient $\gamma_{\circ}^{\mathrm{s}}$, for reactants, transition state and products. Once solvent activity coefficient are available or can be predicted, it is highly probable that enormous amount of information on the kinetics of reactions in solution and on equilibrium properties such as solubility, acid-base strength, and kinetics of reaction in the different solvent can be reduced to a relatively small number of constants $[9,10]$. The solvent activity coefficient is defined as in equation (4) such that $\gamma_{\circ}^{\mathrm{s}}$ is proportional to change in the standard chemical potential, $\mu_{\mathrm{i}}$ of solute 1 , (hypothetically ideal in respect to Henrys law, unimolar solution), on transfer from an arbitrarily chosen reference solvent and another solvent respectively $[11,12]$.

Hence

$$
\mu_{\mathrm{i}}^{\mathrm{s}}=\mu_{\mathrm{i}}^{\circ}+\mathrm{RT} \ln \gamma_{1}^{\mathrm{s}}
$$

if the transmission coefficient is unity, the rate of reaction is given by Eqn. (4).

$$
\text { rate }=\frac{\mathrm{KT}}{\mathrm{h}}\left[\mathrm{X}^{\mp}\right]
$$

where $\mathrm{k}$ is Boltzman constant, $\mathrm{h}$ is planks constant.

For bimolecular reaction $\mathrm{A}+\mathrm{B} \rightleftharpoons\left[\mathrm{X}^{\neq}\right] \rightarrow$ product in the solvent (s), is given by Eqn. (5).

$$
\left[\mathrm{X}^{\ddagger}\right]=\mathrm{K}^{\neq}[\mathrm{A}][\mathrm{B}] \frac{\gamma_{\mathrm{A}}^{\mathrm{s}} \gamma_{\mathrm{B}}^{\mathrm{s}}}{\gamma_{\mathrm{X}^{\ddagger}}^{\mathrm{s}}}
$$

Where $\mathrm{K}^{\neq}$is the thermodynamic equilibrium constant between transition state and reactants.

Thus

$$
\text { rate }=[\mathrm{A}][\mathrm{B}] \frac{\mathrm{KT}}{\mathrm{h}} \mathrm{K}^{\neq} \frac{\gamma_{\mathrm{A}}^{\mathrm{s}} \gamma_{\mathrm{B}}^{\mathrm{s}}}{\gamma_{\mathrm{X}^{\neq}}^{\mathrm{s}}}
$$

and the specific rate constant in a solvent (s) is given by Eqn. (7).

$$
\mathrm{K}^{\mathrm{s}}=\frac{\mathrm{KT}}{\mathrm{h}} \mathrm{K}^{\neq} \frac{\stackrel{\circ}{\gamma_{\mathrm{A}}^{\mathrm{s}}{ }^{\circ} \gamma_{\mathrm{B}}^{\mathrm{s}}}}{\gamma_{\mathrm{X}^{\neq}}^{\mathrm{s}}}
$$

In the standard solvent, $\gamma_{\circ}^{\mathrm{s}}$ is by definition, unity, so that 


$$
\mathrm{K}^{\circ}=\frac{\mathrm{KT}}{\mathrm{h}} \mathrm{K}^{\neq}
$$

and rate constant in the different solvent is related by equation (9) which allows a quantitative prediction of solvent effects on rates of reactions if ${ }^{\circ} \gamma_{i}$ for the solutes and solvent are known or can estimate.

$$
\mathrm{K}^{\mathrm{s}}=\mathrm{K}^{\circ} \frac{{ }^{\circ} \gamma_{\mathrm{A}}^{\mathrm{s}} \stackrel{\circ}{\circ} \gamma_{\mathrm{B}}^{\mathrm{s}}}{{ }^{\circ} \gamma_{\mathrm{X}^{\neq}}^{\mathrm{s}}}
$$

\subsubsection{Thermodynamic Transfer Function}

The thermodynamic transfer function approach of medium change is highly informative concerning transition-state structure enabling one to deduce stable effects of charge distribution and the correlation between medium effects and structure relationships. In 1960s Arnett, amid to explain the variation of the hydrolysis of tetr-butyl chloride in alcoholwater mixture and on the other with Parker"s studies of bimolecular nucleophilic substitution reaction in dipolar aprotic solvents. The latter were found to have very large rate-enhancing properties in many instances as compared with hydroxylic solvents $[13,9]$.

The free energy change $(\S G)$ for the reaction on going from one solvent to another can be measured by measuring solubilities in each solvent and a third immiscible solvent because the reactant in the solvent is in equilibrium with reactant as solid or as a solution in the immiscible solvent. As a result of Parkers measurement the sum of $\S \mathrm{H}, \S \mathrm{S}$ and $\S \mathrm{G}$ for the reactants together can be found, these may then be combined with the value of, $\Delta \mathrm{H}^{\neq}, \Delta \mathrm{S}^{\neq}$and $\Delta \mathrm{G}^{\neq}$for the activation process to get $\S \mathrm{G}$ value for the transition state by equation (10) and (11) and this is illustrated in Figure 2. [13, 14, 15].

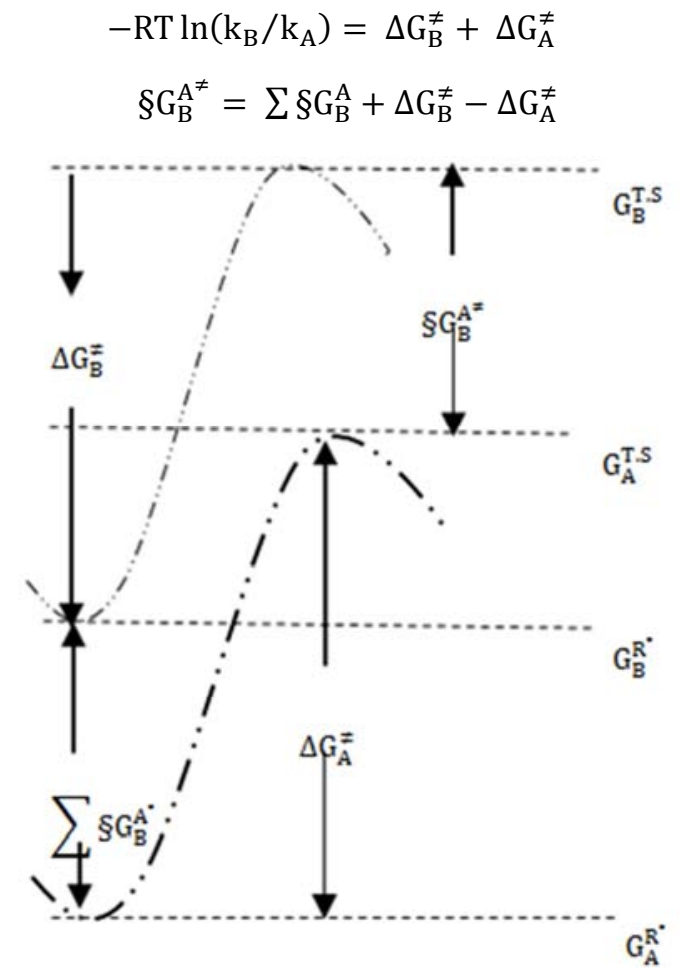

Figure 2. Calculation of the free energy of transition state from solvent $A$ to solvent $B$.
$\Delta \mathrm{G}_{\mathrm{A}}^{\neq}=$change in free energy of activation of solvent A.

$\Delta \mathrm{G}_{\mathrm{B}}^{\neq}=$change in free energy of activation of solvent $\mathrm{B}$.

$\sum \delta \mathrm{G}_{\mathrm{B}}^{\circ}=$ change in standard free energy of transfer of a solute from solvent A to B.

$\S G_{B}^{A^{\neq}}=$change in standard free energy of transfer of transition state from solvent $\mathrm{A}$ to $\mathrm{B}$.

\subsubsection{Kirkwood-Buff Treatment of Preferential Solvation}

The Kirkwood-Buff treatment of liquid systems shows that the thermodynamic properties of a mixture are used to obtain information concerning spatial pair correlation function, $\mathrm{g}_{12}$ $(\mathrm{R}), \mathrm{g}_{22}(\mathrm{R})$ and $\mathrm{g}_{11}(\mathrm{R})$ where $\mathrm{R}$ is the scalar distance. The link between these function and thermodynamics properties through the integral function $\mathrm{G}_{11}, \mathrm{G}_{22}$ and $\mathrm{G}_{12}$. Thus for the integral function $G_{12}$ [10]. It has been observed that by changing the composition of the aqueous system it is possible to control, speed up or slow down a given chemical reaction [16]. The aqueous mixture has been classifying into typically aqueous and typically nonaqueous mixtures. The mixture is classified as typically non-aqueous mixtures if excess molar enthalpies of mixing $\left(\mathrm{H}_{\mathrm{m}}^{\neq}\right)$are large than the excess molar entropies-temperature product i.e $\left(\mathrm{H}_{\mathrm{m}}^{\neq}\right)>\mathrm{TS}_{\mathrm{m}}^{\neq}$. The Kirkwood-Buff treatment of liquid systems was originally aimed at showing how the thermodynamics properties of a mixture could be classified from knowledge of angleaveraged. Pair-correlations functions, $\mathrm{g}_{12}(\mathrm{R}), \mathrm{g}_{22}(\mathrm{R})$ and $\mathrm{g}_{11}$ (R) where $(\mathrm{R})$ is the scalar distance. The link between this function and the thermodynamic properties is established through the integral function $G_{11}, G_{22}$ and $G_{12}$. Thus for the integral function $\mathrm{G}_{12}$,

$$
\mathrm{G}_{12}=\int\left[\mathrm{g}_{12}(\mathrm{R})-1\right] 4 \Pi \mathrm{R}^{2} \cdot \mathrm{dR}
$$

the function $G_{12}$ measures the tendency of molecules of liquid 1 toward the molecules of liquid 2. The inverse Kirkwood-Buff developed by Ben-Naim uses the thermodynamic data of a given mixture to calculate the integral function $\mathrm{G}_{11}, \mathrm{G}_{22}$ and $\mathrm{G}_{12}$. For ethanol (2) and water (1), the function $G_{11}, G_{22}$ and $G_{12}$ have been calculated using excess molar Gibbs free energy molar volumes, and isothermal compressibilities, $\kappa_{\mathrm{i}}$ at $298.2 \mathrm{~K}$ [17]. The integral function expresses the affinity of solute $\mathrm{j}$ for solvent 1 in its cosphere $[17,18]$. The analysis of the rates of reaction in an aqueous solvent in the whole mole fraction ranges and their comparison with molar excess thermodynamics function and Kirkwood-Buff integral functions may yield valuable mechanistic information regarding the transition state. These observations have been known to point out an interesting link extending from kinetics through equilibrium thermodynamics properties of the solution and liquid mixtures to statistical thermodynamics treatment of liquid system.

\section{Method}

\subsection{Kinetic Measurement}

Kinetic Measurement: Atypical kinetic run of the DakinWest reaction were carried out in the following steps, the 
solution of glycine $\left(0.03 \mathrm{~mol} . \mathrm{dm}^{-3}\right)$, pyridine $\left(0.1 \mathrm{~mol} . \mathrm{dm}^{-3}\right)$ and acetic anhydride $\left(0.625 \mathrm{~mol} . \mathrm{dm}^{-3}\right)$ in $\mathrm{Me}_{2} \mathrm{SO}$ were equilibrated in a thermostat for 10 minutes. The required volume of the substrate was transferred to the reaction flask equipped with a reflux condenser. At suitable intervals of time, $2.0 \mathrm{~cm}^{3}$ of the reaction mixture is transferred to a conical flask $\left(100 \mathrm{~cm}^{3}\right)$ containing $2.0 \mathrm{~cm}^{3}$ of hydrochloric acid to stop the reaction by hydrolysis of acetic anhydride to acetic acid and complete the volume to the mark by double distiller water. The concentration of acetic acid at the time $(\mathrm{t})$ was titrated using a standard solution of sodium hydroxide and phenolphthalein as indicator. The pseudo-first order rate constant was determined by the integrated rate law for the first-order reaction and the thermodynamic activation parameters were calculated.

\subsection{Determination of Activity Coefficient}

Activity coefficient was obtained from freezing point depression data for the glycine in $\mathrm{Me}_{2} \mathrm{SO}$ and boiling point elevation for THF and $\mathrm{CH}_{3} \mathrm{CN}$ solvent. This was done by an improved method due to Beckmann, using ordinary freezing point depression apparatus [7]. The activity was obtained from the Eqn. (13).

$$
\mathrm{a}_{\mathrm{Me}_{2} \mathrm{SO}}=\exp \left(\frac{{ }_{\mathrm{H}_{\mathrm{Me}_{2} \mathrm{SO}} \Delta \mathrm{T}_{\mathrm{f}}}}{\mathrm{RT}_{\mathrm{f}}^{2}}\right)
$$

where:

$\mathrm{T}_{\mathrm{f}}=$ Freezing point of $=12.6=6.527 \mathrm{~kJ} \mathrm{~mol}^{-1}$

$\Delta \mathrm{T}_{\mathrm{f}}=$ Freezing point depression

$\mathrm{H}_{\mathrm{f}_{\mathrm{Me}_{2} \mathrm{SO}}}=$ molar heat of fusion of $\mathrm{Me}_{2} \mathrm{SO}=6.527 \mathrm{~kJ} \mathrm{~mol}^{-1}$ and the activity coefficient of the solvent dimethyl

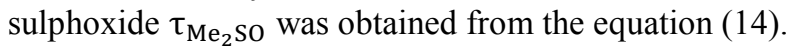

$$
\tau_{\mathrm{Me}_{2} \mathrm{SO}}=\frac{a_{\tau_{\mathrm{Me}_{2} \mathrm{SO}}}}{X_{\tau_{\mathrm{Me}_{2} \mathrm{SO}}}}
$$

where $\mathrm{X}_{\tau_{\mathrm{Me}_{2} \mathrm{SO}}}$ is the mole fraction of $\mathrm{Me}_{2} \mathrm{SO}$ in the various solutions. Finally a plot was made of $\left(\mathrm{X}_{\mathrm{Me}_{2} \mathrm{So}} / \mathrm{X}_{\mathrm{gly}}\right)$ vs $\ln \tau_{\mathrm{Me}_{2} \text { so }}$ where $\mathrm{X}_{\mathrm{gly}}$ is the mole fraction of glycine in solution.

The plotted curve is extrapolated and the area under the curve is determined. The activity coefficient is given by Eqn. (15).

$$
\tau_{\mathrm{Me}_{2} \mathrm{SO}}=\exp ^{(- \text {Area })}
$$

From the boiling point elevation data, the activity and activity coefficient was similarly calculated for $\mathrm{CH}_{3} \mathrm{CN}$ and THF.

\section{Result and Discussion}

\subsection{Base Catalysis of the Dakin-West Reaction}

Base Catalysis on the rate of the reaction was investigated by using the series; pyridine, trimethylamine, tri-nbutylamine, aniline and $O$-nitro aniline in $\mathrm{Me}_{2} \mathrm{SO}$ at 70 . At the rate-limiting step of the reaction is the removal of a proton from the amino acid or its azlactone derivative. It might be anticipated that the catalytic activity of the series of bases would parallel their ionization constant, generally considered as a measure of proton-accepting ability. The rate of reaction in different bases is shown in Table 1.

Table 1. The rate of reaction of glycine with acetic anhydride in various bases.

\begin{tabular}{llll}
\hline Base catalyst & $\mathbf{K} \cdot \mathbf{~ m i n}^{-1} \mathbf{x} \mathbf{1 0}^{-3}$ & $\mathbf{L o g ~ k}$ & $\mathbf{p K}_{\mathbf{b}}$ \\
\hline Triethylamine & 59.62 & -1.22 & 3.20 \\
Tri-n-butylamine & 56.59 & -1.25 & 3.60 \\
Pyridine & 42.35 & -1.37 & 8.80 \\
Aniline & 38.89 & -1.41 & 9.40 \\
O-nitro aniline & 21.43 & -1.67 & 13.00 \\
\hline
\end{tabular}

It can be seen that from the table 1, the bases have a considerable effect on the reaction rate. In the series pyridine, triethylamine and tri-n-butylamine, the higher rate constant can be attributed to the greater electron availability on the nitrogen atom. It seems plausible that the slow rate of the reaction which obtained with aniline and O-nitro aniline is due to the most rapid formation of the conjugated base of an azlactone intermediate. This can interpret in term of proton transfer from azlactone to base in the rate-determining step. This could be due to increasing steric hindrance or increase the energy of dissolvation that must precede proton transfer. This observation support that the transition state is stabilized when pyridine, triethylamine, tri-n-butylamine uses as a catalyst and destabilized in other bases. A plot of $\log k_{o}$ versus $\mathrm{pK}_{\mathrm{a}}$ gave a linear relation, Figure 3, from the slope $(\beta=-0.0277)$ is near zero, this indicates the transition state is very reactant-like and the proton has barely moved in the transition state. There is a negative charge very close to the catalyst and the positive charge developing in the base catalyst is delocalized away from the reaction site. From these finding a quasi-membered ring azalactone was proposed s possible transition state structure.

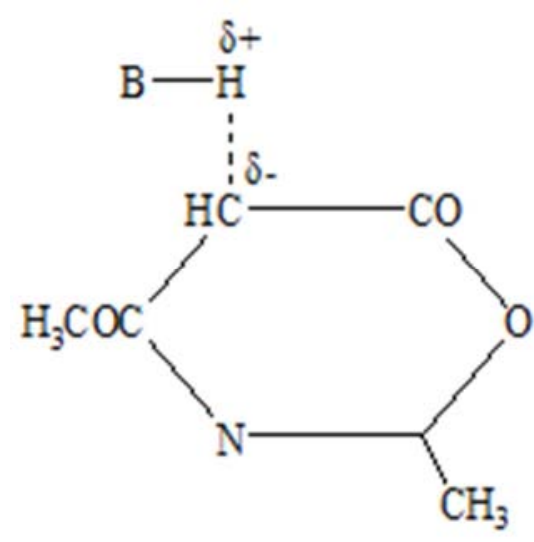

(7a)

King and McMillan suggested the same transition state in the reaction of $O$-chloro phenyl acetic with acetic- $1-\mathrm{c}^{14}$ anhydride in the presence of pyridine [6] 


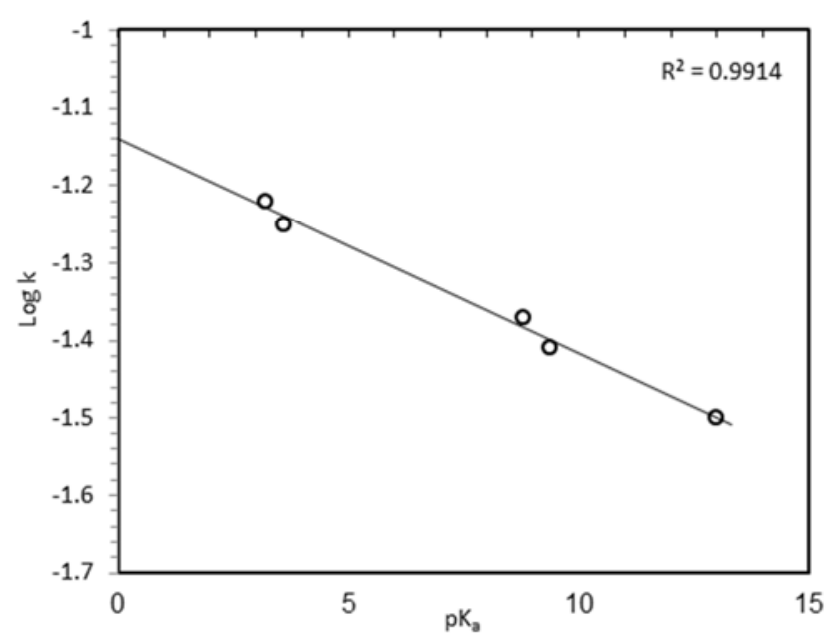

Figure 3. Bronsted dependence of $\log k_{o} v s p K_{b}$ for the reaction of glycine with acetic anhydride.

\subsection{Thermodynamic Transfer Functions}

Differential solvation of initial and transition state is an important tool in mechanistic studies. The solvent effects on the rate of reaction were investigated by changing the solvent from $\mathrm{Me}_{2} \mathrm{SO}$ to $\mathrm{CH}_{3} \mathrm{CN}$ and THF.

\subsection{1. $\mathrm{Me}_{2} \mathrm{SO}$ to $\mathrm{THF}$}

Table 2 records the rate constant, activity coefficient and solubility of reactant glycine with acetic anhydride in $\mathrm{Me}_{2} \mathrm{SO}$ and THF as solvent

Table 2. The rate constant, activity coefficient and solubility of glycine in $\mathrm{Me}_{2} \mathrm{SO}$ and $\mathrm{THF}$ (in mole fraction).

\begin{tabular}{lll}
\hline Parameter & Me $_{2}$ SO & THF \\
\hline Rate constant $\left(\mathrm{k} \cdot \mathrm{min}^{-1}\right) \times 10^{-3}$ & 43.35 & 16.04 \\
Solubility & 0.59 & 0.36 \\
Activity coefficient & 0.17 & 0.12 \\
\hline
\end{tabular}

Comparison of the rate constant in table 4 showed that the reaction in $\mathrm{Me}_{2} \mathrm{SO}$ is faster than THF. The energy of transfer for reactant and transition state for the reaction summarized in table 3 .

Table 3. Thermodynamic analysis of differential solvation at 70 from $\mathrm{Me}_{2} \mathrm{SO}$ to $\operatorname{THF}\left(\mathrm{G}\right.$, in kJ. Mole $\left.{ }^{-1}\right)$.

\begin{tabular}{lc}
\hline $\mathrm{k}_{\mathrm{Me}_{2} \mathrm{so}} / \mathrm{k}_{\mathrm{THF}}$ & +2.61 \\
$\S \mathrm{Ge}_{\mathrm{THF}} \mathrm{Me}_{2} \mathrm{o}^{\circ}$ & +1.91 \\
$\Delta \mathrm{G}_{\mathrm{Me}_{2} \mathrm{so}}^{ \pm}-\Delta \mathrm{G}_{\mathrm{THF}}^{ \pm}$ & +2.18 \\
$\S \mathrm{G}_{\mathrm{THF}}^{\mathrm{Me}_{2} \mathrm{SO}^{\neq}}$ & +4.09 \\
\hline
\end{tabular}

It clearly seen that the initial state is slightly destabilized $\left(\S \mathrm{G}_{\mathrm{THF}}^{\mathrm{Me}_{2} \mathrm{SO}^{\circ}}=+1.91\right)$ also the transition state destabilized on transfer from $\mathrm{Me}_{2} \mathrm{SO}$ to $\mathrm{THF}\left(\mathrm{G}_{\mathrm{THF}}^{\mathrm{Me}_{2} S O^{\neq}}=+2.18\right)$ more than initial state destabilization. The above destabilization is greater in magnitude as compared to the ground state destabilization. This is strong indication of developmentcharge in the transition state which is in accord with the postulated transition state. The negative center in $\mathrm{Me}_{2} \mathrm{SO}$ is on a less hindrance oxygen and interacts more strongly with positive centers in the transition state than does the negative oxygen of THF $[9,10]$. As a result THF solvates positively charged centers poorly and decrease reaction rate. Another factor which may explain the tremendous increase in the rate of reaction in $\mathrm{Me}_{2} \mathrm{SO}$ as compared to the THF is the fact that $\mathrm{Me}_{2} \mathrm{SO}$ is more basic than THF.

\subsection{2. $\mathrm{Me}_{2} \mathrm{SO}$ to $\mathrm{CH}_{3} \mathrm{CN}$}

Table 4 record the rate constant, Activity coefficient and solubility of reactant glycine with acetic anhydride in $\mathrm{Me}_{2} \mathrm{SO}$ and $\mathrm{CH}_{3} \mathrm{CN}$ as a solvent.

Table 4. The rate constant, Activity coefficient and solubility of glycine in $\mathrm{Me}_{2} \mathrm{SO}$ and $\mathrm{CH}_{3} \mathrm{CN}$ (in mole fraction).

\begin{tabular}{lll}
\hline Parameter & $\mathbf{M e}_{2} \mathbf{S O}$ & $\mathbf{C H}_{3} \mathbf{C N}$ \\
\hline Rate constant $\left(\mathrm{k} \cdot \mathrm{min}^{-1}\right) \times 10^{-3}$ & 43.35 & 12.35 \\
Solubility & 0.59 & 0.20 \\
Activity coefficient & 0.17 & 0.09 \\
\hline
\end{tabular}

Comparison of the rate constant in table 6 showed that the rate of reaction in $\mathrm{Me}_{2} \mathrm{SO}$ is faster than the rate of reaction in $\mathrm{CH}_{3} \mathrm{CN}$. The energy of transfer for reactant and transition state for the summarized in table 5 .

Table 5. Thermodynamic analysis of differential solvation at from $\mathrm{Me}_{2} \mathrm{SO}$ to $\mathrm{CH}_{3} \mathrm{CN}(\mathrm{G}$, in $\mathrm{kJ} / \mathrm{mole})$.

\begin{tabular}{lc}
\hline $\mathrm{k}_{\mathrm{Me}_{2} \mathrm{SO}} / \mathrm{k}_{\mathrm{CH}_{3} \mathrm{CN}}$ & +3.51 \\
$\S \mathrm{G}_{\mathrm{CH}_{3} \mathrm{CN}}^{\mathrm{Me}_{2} \mathrm{ON}}$ & +3.86 \\
$\Delta \mathrm{G}_{\mathrm{Me}_{2} \mathrm{SO}}^{\neq}-\Delta \mathrm{G}_{\mathrm{CH}_{3} \mathrm{CN}}^{\neq}$ & +2.85 \\
$\S \mathrm{Ge}_{\mathrm{CH}_{3} \mathrm{CN}}^{\mathrm{Me}^{\neq}}$ & +6.71 \\
\hline
\end{tabular}

Table 5 reveal that the initial state is destabilized $\left(\S \mathrm{G}_{\mathrm{CH}_{3} \mathrm{CN}}^{\mathrm{Me}_{2} \mathrm{O}^{\circ}}=+3.86\right)$ on transfer from $\mathrm{Me}_{2} \mathrm{SO}$ to $\mathrm{CH}_{3} \mathrm{CN}$. Similarly the transition state is also destabilized on this transfer $\left(\mathrm{G}_{\mathrm{CH}_{3} \mathrm{CN}}^{\mathrm{Me}_{2} \mathrm{SO}^{\neq}}=+2.85 \mathrm{~kJ} /\right.$ mole $)$ less than initial state destabilization. These result in overall decrease in reaction rate of reaction. The factor which may explain the tremendous decrease in rate of reaction in $\mathrm{CH}_{3} \mathrm{CN}$ as compared to $\mathrm{Me}_{2} \mathrm{SO}$ is the fact that the negative end of $\mathrm{CH}_{3} \mathrm{CN}$ dipole is significantly less diffuse than the positive end. As a result $\mathrm{CH}_{3} \mathrm{CN}$ solvated positive charge well and negative charge centers poorly. This is a strong indication of negative charge-developing in the transition state which is in accord with postulated transition state (7a). Furthermore $\mathrm{CH}_{3} \mathrm{CN}$ has a very weak basic character. Thus $\mathrm{CH}_{3} \mathrm{CN}$ solvated not by accepting a hydrogen bond from protic donors but essentially through ion-dipole, dipole-dipole and charge dispersion interactions. Therefore the initial and transition state are destabilized and this result in an overall decrease in reaction rate. Another factor which may explain the tremendous increase in the rate of reaction in $\mathrm{Me}_{2} \mathrm{SO}$ as compared to $\mathrm{CH}_{3} \mathrm{CN}$ is fact that $\mathrm{Me}_{2} \mathrm{SO}$ is more basic than $\mathrm{CH}_{3} \mathrm{CN}$ and glycine dissociates well in $\mathrm{Me}_{2} \mathrm{SO}$ than in $\mathrm{CH}_{3} \mathrm{CN}$. 


\subsection{3. $\mathrm{CH}_{3} \mathrm{CN}$ to $\mathrm{THF}$}

Table 6 . records the rate constant, activity coefficient and solubility of reactant glycine with acetic anhydride in $\mathrm{CH}_{3} \mathrm{CN}$ and THF as a solvent.

Table 6. The rate constant, activity coefficient and solubility of glycine in $\mathrm{CH}_{3} \mathrm{CN}$ and $\mathrm{THF}$ (in mole fraction).

\begin{tabular}{lll}
\hline Parameter & $\mathbf{C H}_{3} \mathbf{C N}$ & THF \\
Rate constant $\left(\mathrm{k} \cdot \mathrm{min}^{-1}\right) \times 10^{-3}$ & 12.35 & 16.04 \\
Solubility & 0.20 & 0.36 \\
Activity coefficient & 0.09 & 0.12 \\
\hline
\end{tabular}

Comparison of the rate constant in table 6 showed that the rate of reaction in THF is faster than $\mathrm{CH}_{3} \mathrm{CN}$. The energy of transfer for reactant and transition state for the reaction summarized in table 6 . Table 6 reveals that the initial state is stabilized $\left(\oint_{\mathrm{THF}}^{\mathrm{CH}_{3} \mathrm{CN}^{\circ}}=-2.50\right)$ on transfer from $\mathrm{CH}_{3} \mathrm{CN}$ to THF. Similarly, the transition state is also stabilized on this transfer $\left(\mathrm{S}_{\mathrm{THF}}^{\mathrm{CH}_{3} \mathrm{CN}^{\neq}}=-0.75 \mathrm{~kJ} /\right.$ mole $)$ less than initial state stabilization. This results in an overall increase in reaction rate.
Table 7. Thermodynamic analysis of differential solvation at from $\mathrm{CH}_{3} \mathrm{CN}$ to $T H F$ ( $G$, in $\mathrm{kJ} / \mathrm{mole})$.

\begin{tabular}{|c|c|}
\hline $\mathrm{k}_{\mathrm{CH}_{3} \mathrm{CN}} / \mathrm{K}_{\mathrm{THF}}$ & +0.77 \\
\hline$\S \mathrm{G}_{\mathrm{THF}}^{\mathrm{CH}_{3} \mathrm{CN}^{\circ}}$ & -2.50 \\
\hline$\Delta \mathrm{G}_{\mathrm{CH}_{3} \mathrm{CN}}^{\neq}-\Delta \mathrm{G}_{\mathrm{THF}}^{\neq}$ & -1.80 \\
\hline$\S \mathrm{G}_{\mathrm{THF}}^{\mathrm{CH}_{3} \mathrm{CN}^{*}}$ & -0.75 \\
\hline
\end{tabular}

The stabilization of the transition state is small in magnitude as compared to the ground state which is highly stabilized. This is a strong indication of a negative charge development in the transition state which in accord with postulated transition state (7a). The factor which may explain the tremendous decrease in the rate of reaction in $\mathrm{CH}_{3} \mathrm{CN}$ is due to the poorly solvates of positive charge in the transition state by $\mathrm{CH}_{3} \mathrm{CN}$ as compared to the THF solvates.

\subsection{Aqueous Solvent Effect}

The reaction was further investigated in aqueous $\mathrm{Me}_{2} \mathrm{SO}$, $\mathrm{CH}_{3} \mathrm{CN}$ and THF. The results are listed in Table 8.

\subsection{1. $\mathrm{Me}_{2} \mathrm{SO}-\mathrm{H}_{2} \mathrm{O}$ Binary System}

The rate constant increase when water is added to $\mathrm{Me}_{2} \mathrm{SO}$ reaching a maximum at $\mathrm{X}_{\mathrm{Me}_{2} \mathrm{SO}}=0.2$ and decrease as $\mathrm{X}_{\mathrm{H}_{2} \mathrm{O}}$ increase in $\mathrm{Me}_{2} \mathrm{SO}-\mathrm{H}_{2} \mathrm{O}$ mixture (Figure 4).

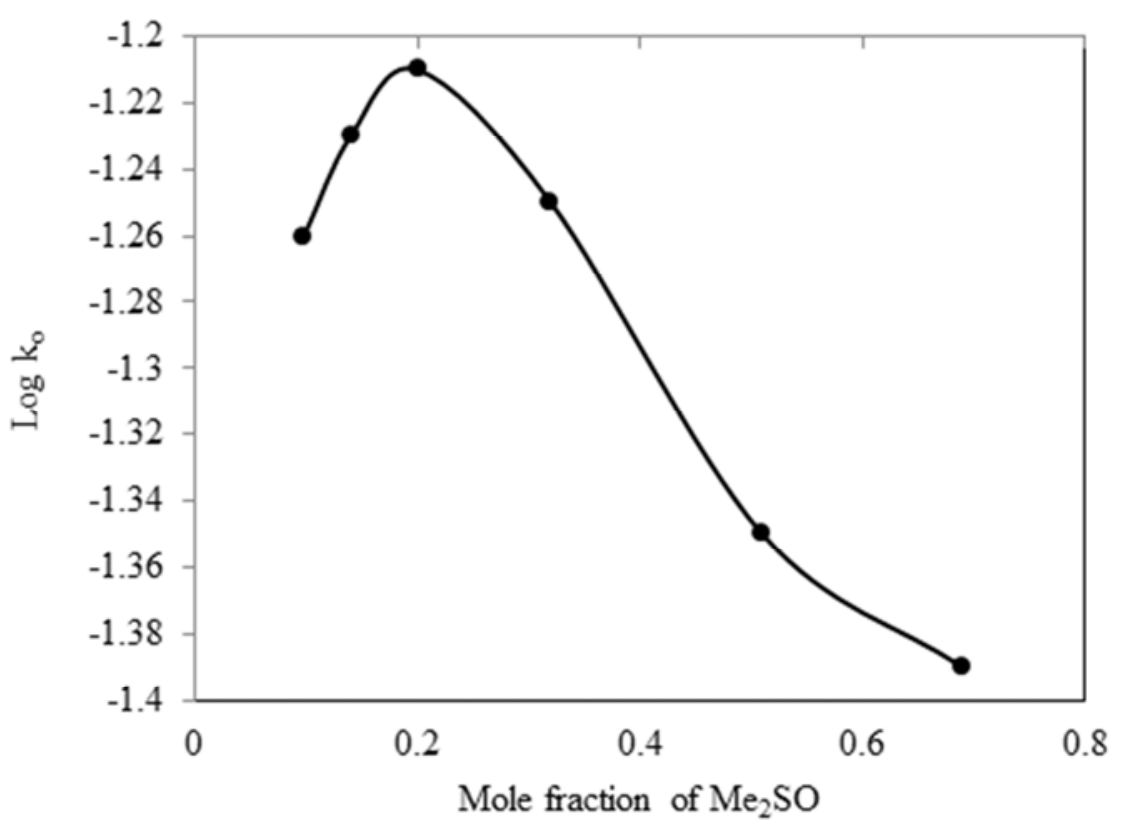

Figure 4. Variation of rate with mole fraction of aqueous $\mathrm{Me}_{2} \mathrm{SO}$.

The dipole-dipole interaction between $\mathrm{Me}_{2} \mathrm{SO}$ and $\mathrm{H}_{2} \mathrm{O}$ molecules appear to play a role increase of rate constant and evidence for this come from Raman spectra and n. m. $r$ spectra of $\mathrm{Me}_{2} \mathrm{SO}-\mathrm{H}_{2} \mathrm{O}$ mixture [22]. Consequently it seems as if the transition state prefers the $\mathrm{H}_{2} \mathrm{O}$ domain to the $\mathrm{Me}_{2} \mathrm{SO}$ domain. Therefore the postulated transition state (7a), which is charged should be highly stabilized when $\mathrm{H}_{2} \mathrm{O}$ is added to $\mathrm{Me}_{2} \mathrm{SO}$ and the ground state being destabilized or less stabilized than the transition state and this is observed from the increased of reaction rate. Eero also made the same observation in the acid hydrolysis of ethyl acetate in $\mathrm{Me}_{2} \mathrm{SO}-\mathrm{H}_{2} \mathrm{O}$ mixture $[19,20]$. On the other hand the ground state is destabilized as an uncharged species will prefer the $\mathrm{Me}_{2} \mathrm{SO}$ domain to the $\mathrm{H}_{2} \mathrm{O}$ domain $[10,21]$. When water is mixed with $\mathrm{Me}_{2} \mathrm{SO}$ much heat is evolved and the mixture becomes viscous for a short time. This may result from breakdown of $\mathrm{Me}_{2} \mathrm{SO}$ order and formation of hydrogen bonded $\mathrm{S}=\mathrm{O} \ldots . . \mathrm{H}_{2} \mathrm{O}$ which are more strongly bonded. This is responsible for the stabilization of transition state and increase in reaction rate. The interaction in $\mathrm{Me}_{2} \mathrm{SO}(2)-\mathrm{H}_{2} \mathrm{O}$ (1) system are further 
Table 8. Rate constant in aqueous $\mathrm{Me}_{2} \mathrm{SO}, \mathrm{CH}_{3} \mathrm{CN}$ and THF.

\begin{tabular}{|c|c|c|c|c|c|c|c|c|c|c|c|}
\hline $\mathrm{Me}_{2} \mathrm{SO}$ & & & THF & & & DMF & & & $\mathrm{CH}_{3} \mathrm{CN}$ & & \\
\hline Mole fraction & $K_{0} \times 10^{3}$ & $\log k_{0}$ & Mole fraction & $K_{0} \times 10^{3}$ & $\log k_{0}$ & Mole fraction & $K_{0} \times 10^{3}$ & $\log k_{0}$ & Mole fraction & $K_{0} \times 10^{3}$ & $\log k_{0}$ \\
\hline 0.69 & 40.96 & -1.39 & 0.75 & 6.40 & -2.19 & 0.68 & 11.28 & -1.95 & 0.66 & 10.00 & -2.00 \\
\hline 0.51 & 45.00 & -1.35 & 0.58 & 10.86 & -1.96 & 0.48 & 8.55 & -2.08 & 0.45 & 7.027 & -2.14 \\
\hline 0.32 & 56.00 & -1.25 & 0.39 & 13.33 & -1.88 & 0.30 & 3.00 & -2.52 & 0.29 & 5.68 & -2.25 \\
\hline 0.20 & 61.00 & -1.21 & 0.26 & 13.60 & -1.87 & 0.19 & 4.69 & -2.33 & 0.18 & 4.69 & -2.33 \\
\hline 0.14 & 58.00 & -1.23 & 0.19 & 12.50 & -1.90 & 0.14 & 6.25 & -1.20 & 0.13 & 5.15 & -2.29 \\
\hline 0.098 & 55.00 & -1.26 & - & - & - & - & - & - & 0.09 & 6.25 & -2.20 \\
\hline
\end{tabular}

supported by the inverse Kirkwood-Buff integrals (Figure 5). Across most of the mole fraction range, $\mathrm{G}_{12}$ is large than either $\mathrm{G}_{11}$ or $\mathrm{G}_{22}$, showing no dramatic dependence on $\mathrm{x}_{2}$, in other word there is a strong possibility of finding water molecules and $\mathrm{Me}_{2} \mathrm{SO}$ molecule in close proximity this consistent which strong directional hydrogen bonding between the two components. Thus $\mathrm{Me}_{2} \mathrm{SO}(2)-\mathrm{H}_{2} \mathrm{O}(1)$ is typically non-aqueous system with both $\mathrm{G}_{\mathrm{E}}^{\mathrm{m}}$ and $\mathrm{H}_{\mathrm{E}}^{\mathrm{m}}$ being negative (Figure 6) and this is consistent with strong inter component interaction. A significant observation is that both $\mathrm{G}$ and $\mathrm{H}$ have their minima and $\mathrm{T}$. $\mathrm{S}$ its maximum at

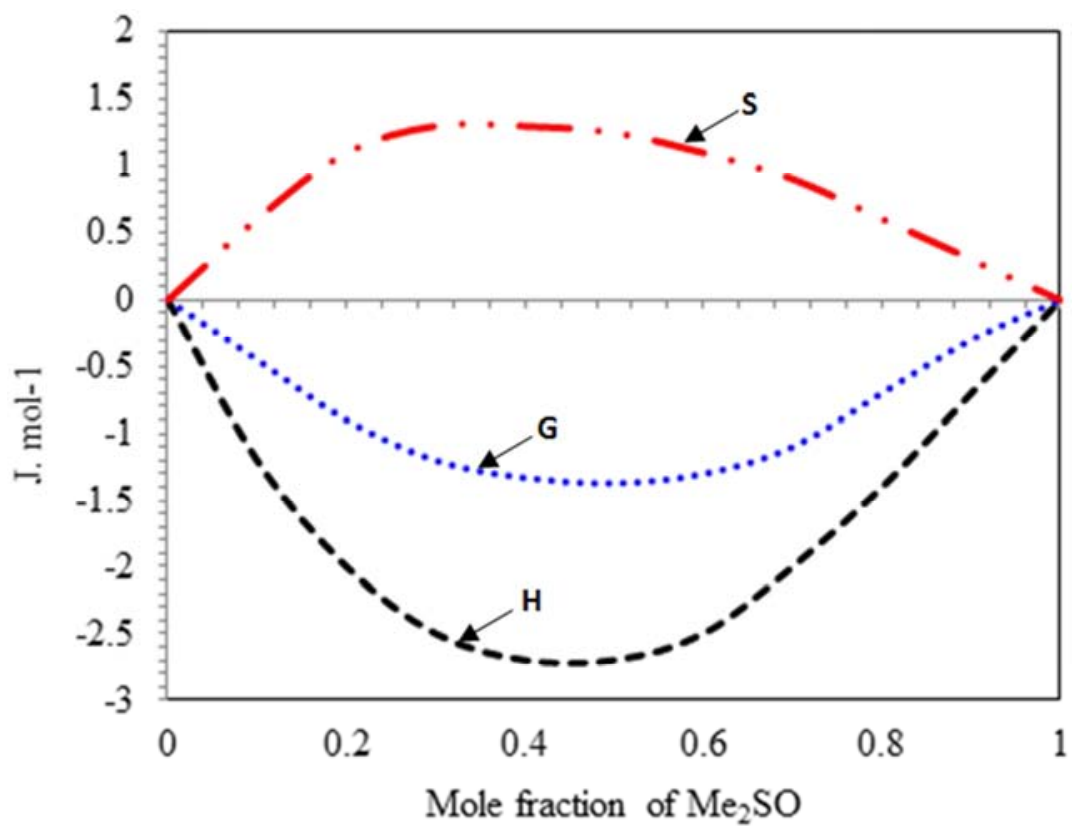

Figure 5. Molar Excess thermodynamic properties for $\mathrm{Me}_{2} \mathrm{SO}(2)-\mathrm{H}_{2} \mathrm{O}(1)$ mixture at [22].

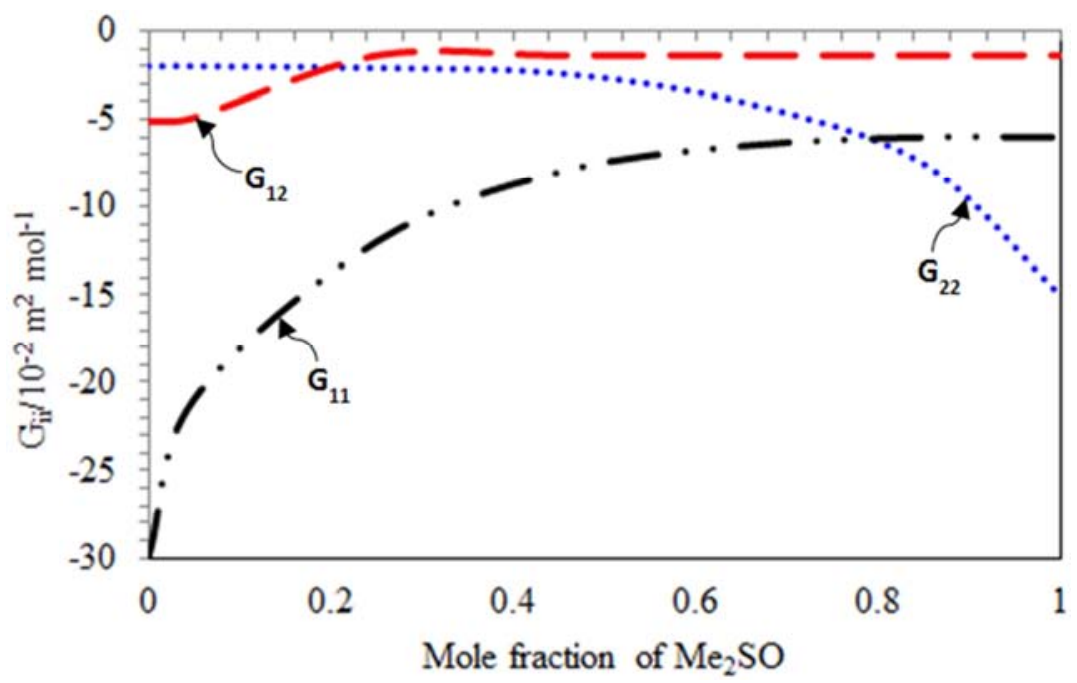

Figure 6. Inverse Kirkwood-Buff integral function for $\mathrm{Me}_{2} \mathrm{SO}(2)-\mathrm{H}_{2} \mathrm{O}(1)$. 


\subsection{2. $\mathrm{CH}_{3} \mathrm{CN}-\mathrm{H}_{2} \mathrm{O}$ Binary System}

The rate constant decreased when water is added to the $\mathrm{CH}_{3} \mathrm{CN}$ reaching a minim at $\mathrm{x}_{\mathrm{CH}_{3} \mathrm{CN}}=0.18$ followed by a slight increase in reaction rate. The decrease in reaction rate could be attributed to the lack of interaction between $\mathrm{CH}_{3} \mathrm{CN}$ and $\mathrm{H}_{2} \mathrm{O}$ molecules. Consequently, it seems the charged transition state prefers the $\mathrm{CH}_{3} \mathrm{CN}$ domain to the $\mathrm{H}_{2} \mathrm{O}$ domain. Therefore the postulated transition state (7a) which is charged should be destabilized when $\mathrm{H}_{2} \mathrm{O}$ is added to
$\mathrm{CH}_{3} \mathrm{CN}$ and the ground state being stabilized or less destabilized than transition state. The decrease in reaction rate due to the breakdown of solvent structure of $\mathrm{CH}_{3} \mathrm{CN}$ and formation of Structure such as $\mathrm{CH}_{3} \mathrm{C}=\mathrm{N}$.....HOH.... $\mathrm{N}=\mathrm{CCH}_{3}$ which is responsible for the destabilization of the transition state and reduced reaction rate [23].

$\mathrm{CH}_{3} \mathrm{CN}(2)-\mathrm{H}_{2} \mathrm{O}(1)$ is classified as typically non-aqueous mixture positive and the excess enthalpy of $\mathrm{CH}_{3} \mathrm{CN}(2)$ $\mathrm{H}_{2} \mathrm{O}(1)$ is positive at low temperature (Figure 7) $[25,26]$.

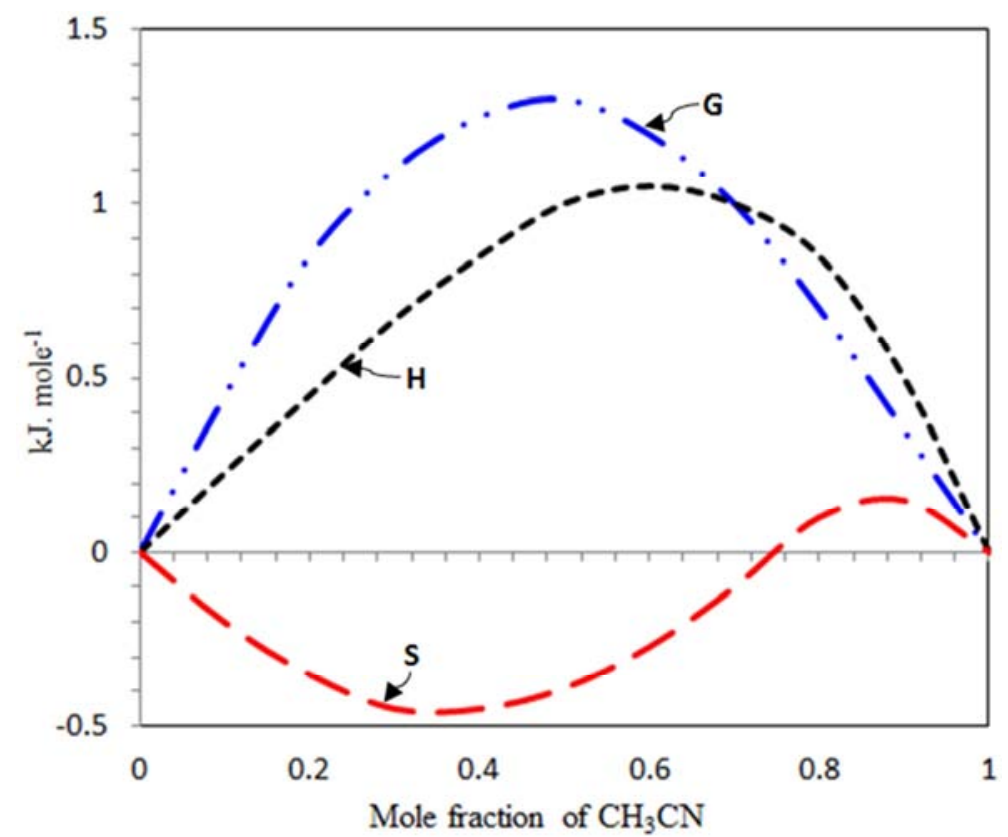

Figure 7. Molar excess thermodynamic properties for $\mathrm{CH}_{3} \mathrm{CN}(2)-\mathrm{H}_{2} \mathrm{O}(1)$ mixtures at $298 \mathrm{~K}$. [22].

Evidence of this is further obtained from the KirkwoodBuff integral function. The maxima in $\mathrm{G}_{11}$ and $\mathrm{G}_{12}$ (Figure 8) show that the probabilities of finding $\mathrm{H}_{2} \mathrm{O}$ in close proximity to $\mathrm{H}_{2} \mathrm{O}$ molecules and $\mathrm{CH}_{3} \mathrm{CN}$ molecules in close proximity to $\mathrm{CH}_{3} \mathrm{CN}$ molecules are high. On the other hand, the minimum in $G_{12}$ shows that the probability of finding a $\mathrm{CH}_{3} \mathrm{CN}$ molecules near an $\mathrm{H}_{2} \mathrm{O}$ molecule is very low. That is $\mathrm{CH}_{3} \mathrm{CN}$ molecules cluster in $\mathrm{CH}_{3} \mathrm{CN}$ rich domains while $\mathrm{H}_{2} \mathrm{O}$ molecules cluster in $\mathrm{H}_{2} \mathrm{O}$ rich domains [22].

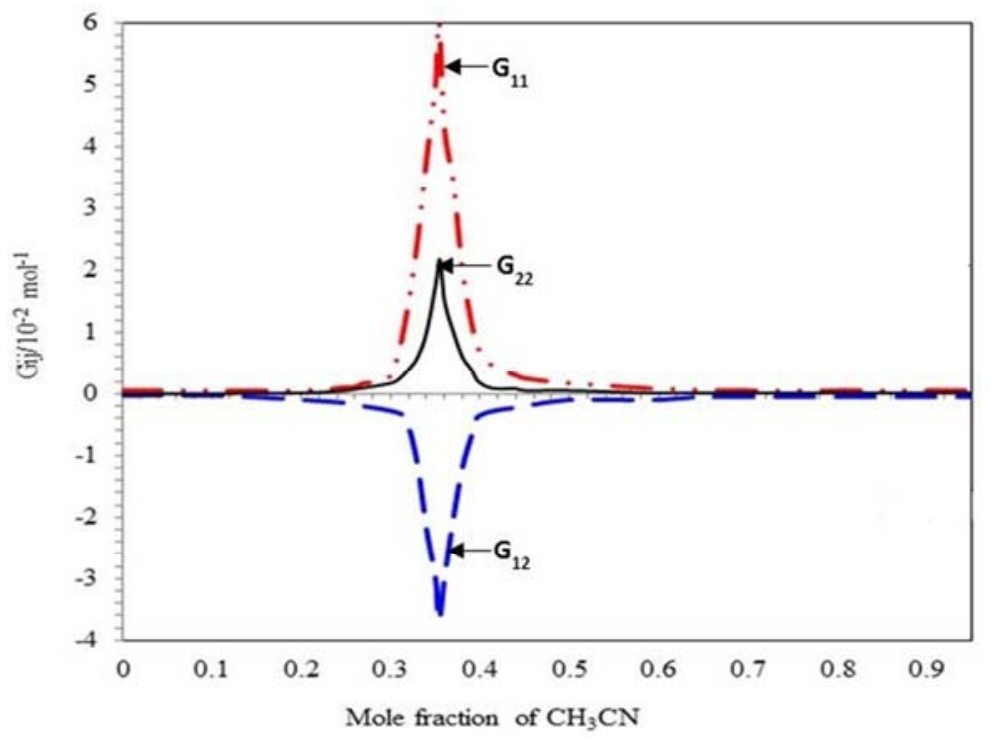

Figure 8. Inverse Kirkwood-Buff Integral Function for $\mathrm{CH}_{3} \mathrm{CN}(2)-\mathrm{H}_{2} \mathrm{O}(1)$. 


\subsection{3. $\mathrm{THF}-\mathrm{H}_{2} \mathrm{O}$ Binary System}

The rate constant increases when water is added to THF rich maximum at $\mathrm{x}_{\mathrm{THF}}=0.26$ and decreases as $\mathrm{x}_{\mathrm{H}_{2} \mathrm{O}}$ than pure $\mathrm{H}_{2} \mathrm{O}$ and THF increase. The increase in reaction rate due to a hydrogen bond between the $\mathrm{H}_{2} \mathrm{O}$ and THF molecules is stronger [27, 28]. The increase in the rate of reaction could be explained by the fact that there is considerable interaction between THF and $\mathrm{H}_{2} \mathrm{O}$ molecules. The increase in reaction rate on the addition of $\mathrm{H}_{2} \mathrm{O}$ could be an indication that the transition state, which is charged, could be stabilized and ground state destabilized. Consequently, the postulated transition state $(7 \mathrm{a})$ charged prefers the $\mathrm{H}_{2} \mathrm{O}$ domain to the THF domain. The increase in reaction rate in the region $0.39>x_{2}>0.26$ seems to be simply connected with the decrease of THF content in the mixture and in this region the transition state is stabilized and ground state destabilized or less stabilized by this interaction. In the $\mathrm{x}_{\mathrm{THF}}>0.19$ the rate constant decrease as increase the mole fraction of water which suggests less interaction water and THF molecules and in this region the ground state id stabilized and transition state destabilized or less stabilized resulting in reduced rate constant. Therefore the central attractive force between THF and its adjacent water further decrease the rate and enhance the water reorientation and decrease in reaction rate due to water interaction with second-nearest water neighbors are replaced by stronger Van der Waals interaction with the close THF. As more $\mathrm{H}_{2} \mathrm{O}$ is added competition of the oxygen atom for H-bond formation leads to replacement of net-work THF$\mathrm{H}_{2} \mathrm{O}$ bond by water-water bond which is responsible for the observed minimum in reaction rate [29].

$\mathrm{THF}(2)-\mathrm{H}_{2} \mathrm{O}(1)$ is a member of typically aqueous mixture with excess function is positive is large and negative such that. The thermodynamic excess function of $\mathrm{THF}(2)-\mathrm{H}_{2} \mathrm{O}(1)$ are shown in (Figure 9) an interesting feature is an almost linear dependence of on over the range where the mixing change from exothermic evidently as increase to water-water hydrogen bond is replaced by water-THF hydrogen bond [10, 30].

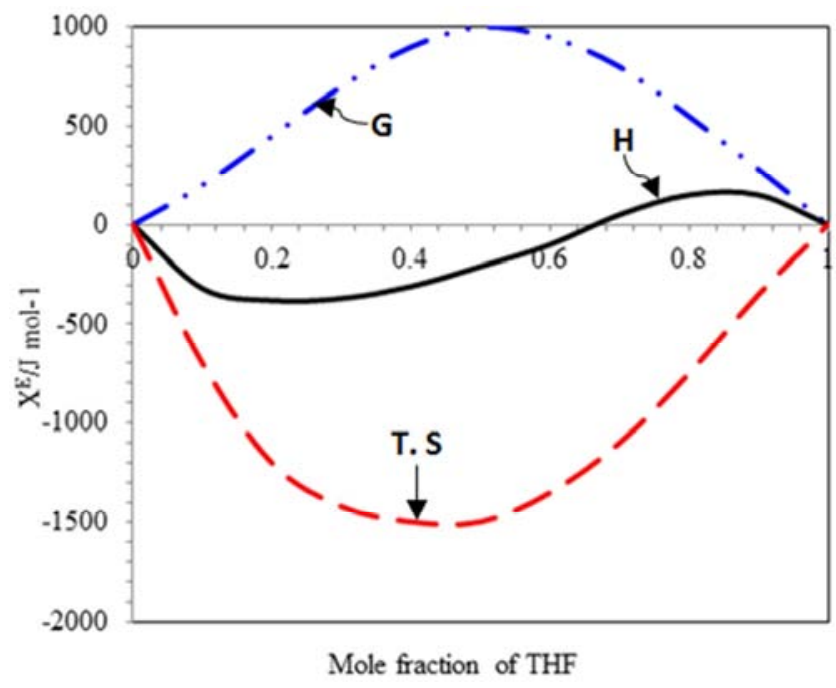

Figure 9. The excess thermodynamic function of mixing $\mathrm{THF}-\mathrm{H}_{2} \mathrm{O}$ mixture. [30].

\section{Conclusion}

From the result and discussion arising from experimental observation it is most likely that the reaction mechanism proceeds through acetylation of glycine, cyclization of acetylated product to an azalactone and the reaction of azalactone with pyridine to give resonance stabilized carbanion, followed by the rate determining step. Subsequent step are fast leading to the formation of the acetamido ketone. The Bronsted catalysis equation also in agreement with the postulated transition state structure as depicted by a slope of -0.0277 in the Bronsted plot. This is consistent and supported the transition state structure in which there is a negative charge very close to the catalyst, and the positive charge developing in the base catalyst is delocalized away from the reaction site, indicating. The transition-state is reactant - like. Thermodynamic transfer function from $\mathrm{Me}_{2} \mathrm{SO}$ to $\mathrm{CH}_{3} \mathrm{CN}\left(\mathrm{G}_{\mathrm{CH}_{3} \mathrm{CN}}^{\mathrm{Me}_{2} \mathrm{SO}^{\neq}}=+2.85 \mathrm{~kJ} /\right.$ mole $)$ shown that the transition state is destabilized. The destabilization of transition state on this transfer is in accord with an observation that the negative charge development in the transition state are less solvated by $\mathrm{CH}_{3} \mathrm{CN}$ than by $\mathrm{Me}_{2} \mathrm{SO}$. The transition state structure is further supported by the Kirkwood-Buff treatment of preferential solution. The increase in the rate of reaction when water is added to $\mathrm{Me}_{2} \mathrm{SO}$ could be an indication that the transition state stabilized and the ground state destabilized by this interaction. The same argument applied to $\mathrm{CH}_{3} \mathrm{CN}-\mathrm{H}_{2} \mathrm{O}$ and TFF- $\mathrm{H}_{2} \mathrm{O}$ system has a totally a positive effect on the transition state as evidenced by the decrease rate of the reaction in addition of water to solvent molecules due to lack of interaction between solvent and $\mathrm{H}_{2} \mathrm{O}$ molecules highly destabilized the transition state

\section{References}

[1] N. L. Allinger, G. L. Wang, and B. B. Dewlhurst. (1988) The Dakin - West Reaction. Chem. Soc. Rev. 17, 91-109.

[2] G. H. Cleland and Neiman (1949). Some observation on the Dakin - West Reaction. J. Am Chem. Soc. 71: 841.

[3] G. L. Buchana (1988) The Dakin -West Reaction. Chem. Soc. Rev. 17: 91.

[4] R. A. Y. Jones (1979) Physical and mechanistic of organic chemistry. New York, London, p. 67.

[5] L. P. Hammett (1940) Physical organic chemistry. McMarw Hill Book Co., in., New York.

[6] J. A. King and F. H. McMillan (1955) The Decarboxylative Acylation of $\alpha$-substituted acid. J. Am. Chem. Soc. 77(10): 2814.

[7] M. H. Abraham (1974). Prog. Phys. Org. Chem. 11: 2.

[8] E. M. Arrnett, W. G. Benntrude, J. J. Burke (1965) Solvent Effects in Organic Chemistry. V. Molecules, Ions, and The Transition States in Aqueous Ethanol. J. Am. Chem. Soc. 87: 1544. 
[9] A. J. Parker (1969) Protic - dipolar aprotic solvent effect on rates of bimolecular reaction Chem. Rev. 9: 1.

[10] M. J. Blandamer (1977) Kinetics solvent effect on hydrolysis of ethyl chloroformate in binary aqueous mixtures. Adv. Phys. Org. Chem 14: 203.

[11] A. J. Parker (1968) The Chemistry of Nonaqueous Solvents VA: Principles and Applications. J. Chem. Soc. A: 220.

[12] A. Ben-Naim (1977) Inverse of the Kirkwood-Buff theory of solution: Application to the water - ethanol system. J. Chem. Phys. 67: 4884.

[13] A. J. Parker, U. Mayer, R. Schmid, and V. Gutmann (1973) J. Org. Chem. Soc.; 43; 1834;

[14] R. Elexander, A. J. Parker, J. H. Sharp and W. E. Waghrone (1972) Solvation of ions. XVI. Solvent activity coefficients of single ions. Recommended extra thermodynamic assumption. J. Am. Chem. Soc. 94: 1148.

[15] B. G. Cox, A. J. Parker, J. Am. Chem. Soc.; 95; 408888; (1973).

[16] R. Knorr and R. Huisgen (1970) Mechanism of the Dakin West reaction. 1. Reaction of secondary $\mathrm{N}$-acylamino acid with acetic anhydride. Chem. Ber. 103: 2598.

[17] R. Knorr and R. Huisgen (1971) Mechanism of the Dakin West reaction. 111. Course of ring opening during the Dakin West reaction of an oxazoline - 5 olate. Chem. Ber. 104: 3621 .

[18] R. Knorr and G. K. Staudinger (1971) Mechanism of the Dakin -West reaction. 11. Acylation of Oxazoline - 5-ones by carboxylic anhydride-pyridine. Chem. Ber. 104: 3633.

[19] E. Tomila and M. Murto (1963) the influence of the solvent on reaction velocity, XXIV. The acid hydrolysis of ethyl acetate in dimethyl sulphoxide - water mixture. Acta. Chem. Scand. 17: 1943 .

[20] E. Tomila and M. Savolainen (1966) The Influence of the Solvent on Reaction Velocity. XXXI. The Reaction between Benzyl Chlorides and Methoxide Ion in Dimethyl SulphoxideMethanol Mixtures. Acta. Chem. Scand. 20: 946.
[21] P. P. Bell (1973) the proton in Chemistry. 2 nd, ed. Chapman \& Hall. London. Chapter 5: 69.

[22] M. J. Blandamer, N. J. Blundel, J. Burgess, J. Cowles, J. Hom (1990) An inverse Kirkwood-Buff treatment of the thermodynamic properties of DMSO-water mixtures and cyano methane-water binary liquid mixtures at $298.2 \mathrm{~K}$. J. Chem. Soc. Faraday Trans. 86(2): 277.

[23] M. K. Chantooni and M. Kolthoff (1967) Transfer Activity Coefficients between Water and Methanol of Complexes of Some Univalent and Barium Ions with Dibenzocryptand 2.2.2, Cryptand 2.2.2, and 18-Crown-6. J. Am. Chem. Soc. 89: 1582.

[24] M. K. Chantooni and M. Kolthoff (1967) Hydration of undissociated salts in acetonitrile. J. Am. Chem. Soc. 89: 2521.

[25] J. D. Roberts and W. T. Moreland (1953) Electrical Effects of Substituent Groups in Saturated Systems. Reactivity's of 4Substituted Bicyclo [2.2.2] octane-1-carboxylic Acids. J. Am. Chem. Soc. 75: 2167.

[26] R. W. Taft (1952) Polar and Steric Substituent Constants for Aliphatic and o-Benzoate Groups from Rates of Esterification and Hydrolysis of Esters J. Am. Chem. Soc. 74: 3120.

[27] N. Glew, H. Watts (1971) Aqueous Nonelectrolyte Solutions. Part IX. Enthalpies of Mixing of Water and Deuterium Oxide with Ethylene Oxide. Can. J. Chem. 49: 1830.

[28] D. N. Glew, and N. S. Rath (1971) $\mathrm{H}_{2} \mathrm{O}$, $\mathrm{HDO}$, and $\mathrm{CH}_{3} \mathrm{OH}$ Infrared Spectra and Correlation with Solvent Basicity and Hydrogen Bonding. Can. J. Chem. 49: 837.

[29] D. N. Glew, H. D. Mak, and N. S. Rath (1968) Aqueous nonelectrolyte solutions. Water stabilization by nonelectrolytes. Chem. Commun. 264.

[30] C. Treiner (1975) Thermodynamic transfer functions for urea and thiourea from water to water-tetrahydrofuran mixtures from precise vapor-pressure measurements. J. Chem. Phys. 4: 471-483. 